\title{
Blockchain Based Registration Model for Higher Education
}

\author{
Megha Upreti ${ }^{1}$, Marviola Hardini ${ }^{2}$, Rissa Rahmania ${ }^{3}$ Chandra Abianto ${ }^{4}$ \\ Graphic Era Hill University ${ }^{1}$, University of Raharja ${ }^{2,4}$, Binus University ${ }^{3}$ \\ Sattal Rd, Bhimtal, Uttarakhand 263156, India ${ }^{1}$ \\ Jl. Jenderal Sudirman No.40, RT.002/RW.006, Cikokol, Kec. Tangerang, Kota Tangerang, \\ Indonesia 2,4 \\ JI. K. H. Syahdan No. 9, Kemanggisan, Palmerah, Jakarta 11480 Indonesia $^{3}$ \\ e-mail: mupreti@gehu.ac.in ${ }^{1}$, marviola@raharja.info ${ }^{2}$, rissa.rahmania@binusac.id ${ }^{3}$, \\ chandra.abianto@raharja.info ${ }^{4}$
}

Megha Upreti, Marviola Hardini, Rissa Rahmania, \& Abianto, C. . (2021). Blockchain-Based Registration Model for Higher-Education. Blockchain Frontier Technology, 1(01), 67-72. Retrieved from

DOI: https://journal.pandawan.id/b-front/article/view/16

\begin{abstract}
Education is one of the activities carried out by students and students in order to obtain a title. The process that is common in edification method in Indonesia is a legal action that is done via academic credit at school institutions and must be completed if you want to get recognition in the issuance of a diploma. In Indonesia, a learning activity is full of semi-computer processes but not all educational institutions have implemented this technology. In cases like this, an individual may look for loopholes to commit fraud, such as falsifying diplomas. To find a solution to the problems above, we need to digitize, what is it? Digitization is one of the system that can offer a sense of security and can minimize bureaucracy in the document legal action of ratification with savings on retention and manpower used. A tips passed by students before receiving an academic diploma at one of the universities are starting with the registration process, after all the registration processes are completed, a student is officially accepted at the university and can directly participate in teaching and learning activities, at the time of graduation, it is certain that a student must pass all courses and have completed all the tasks that have been given until he is officially declared graduated. Problems that often occur in the field of education, especially when it is in the registration process, are data falsification, data manipulation, and even the worst case is data loss, this fraud is usually carried out by irresponsible parties. This journal aims to submit a proposal for the schoolboy registry process of school institute in digitalization education method in Indonesia using Blockchain technology. This study resulted in a student enrollment model in an educational institution using Blockchain to supply transparent and validated data in educational process.
\end{abstract}

Keywords: Blockchain, Higher Education, Smart Contract, Registration Student, Model.

\section{Introduction}

High edification has growth notably around the society today. Some category of individuals can enter high edification levels. Most persons pursuing high edification are give them superior occupation with big salaries. In Indonesia, lots of universities has develops, college in Indonesia have reached over 2000 campuses. In Nusantara, the method of education is filled by semi-computerized procedure (not all). The operation of an education gives rise to 
disputes for the issuance of fake academic certificates, and this is due to the desire to get a high paying job.

The development of education today is influenced by numerous exploitations, that is technology using in the current digital era. All of this evolution could replace the humanities of activation procedure; academic institute should provide creative plan that all important side has the ability to make use of technology. Empowerment of this technology happens all the time, and persons can interrelate with thousands of details and statistics around the world. As a tread in replacement, academic institute have to advocate creative manner to every stakeholders for indorse itself using technology. These evolution even offer discussion inside numerous feature, that is particular of integration, pathway, ratification, along with the correctness through data, however from actuality which happen, not every characteristic is fulfilled. In case every aspect could resolved, after each of side could look for it, possess trusted details. It facet could suggested by the contemporary growth of technology by notion distribution, retention, along with non-manipulable ledgers within shape of Blockchainm.

Distributed Ledger is a concept that used in Blockchain, validated with approval as well as involved inside cryptographic algorithms. Satoshi Nakamoto is a first person who created these concept back in 2008 furthermore it's applied to Bitcoin. With its development, a concept in Blockchain is merged with smart contract an idea invented by Nick Szabo, therefore it can be applied in many industrial area as a company system. So that push some huge enterprises like Intel, Microsoft, IBM to develop Blockchain technology.

In education world, plentiful processes that carried, so as someone can become an student at an educational institution, including: registration, lecture activities, extracurricular agenda as well as graduation. The first of it's research shall discuss about details a student on the Blockchain will be recorded, which is the first step of using Blockchain technology for registry a Student. In a few procedure, based on this research, the researchers applied a Blockchain technology to the education world within process of registry student. The registration process is a requirement for a student to be able to carry out the educational process until graduation. with an identity like now, it motivates to provide students a special identification that students can using and can be express properly enrolled in the college so as can't be exploited or include with not legitimate data. This also indirectly protects the circulation of fake diplomas by irresponsible parties.

\section{Literature Review}

Blockchain is a new technology developed for digital data storage systems. Also known as ledger technology that distributed, it is the fundamental building block that provides the graphical data of various virtual currencies. Then DLT is another way of being able to breakthrough many industries, with much of its potential being revealed in the midst of a pandemic. Even in the field of education can be helped from this one technology lately.

4 years ago, one of the universities in Australia has considered starting the use of Blockchain technology as a step to print digital-based credentials for students, this provides an opportunity for students to store their verified data and of course it cannot be simply "tampered with" by other party. Surprisingly enough, 2 years ago, Gartner conducted a survey that aimed to ask and answer questions with respondents from academic institutions about how the process of implementing Blockchain technology is currently running in the education sector.

An impressive example of Blockchain implementation at the university level is being able to convert digital certificates and credentials that are still under the supervision of the student, without the need to use intermediary services to help verify the authenticity of the digital document. Blockchain is indeed a very multifunctional technology, one of the advantages of Blockchain is that it can verify the quality of an institution to measure the level of proficiency of the teacher.

This technology also has the advantage of improving notation, because that is why it can help IPR management to solve various problems, one of which is by using Distributed Ledger Technology to create new ideas or also include copyrights and patents. Blockchainbased on-campus diploma printing is a big breakthrough for the future, but the most important 
example of implementation may be the creation of virtual transcripts and all records of a student's achievements while still in college.

A verified lifetime record will prevent fraud, help complete the process of transferring a student to another University, cut the overhead associated with mail verification and make communication between countries smoother. Actions like this can make efforts to complete the process faster and be efficient in use.

\section{Troubleshooting}

Blockchain technology also plays an active role in the country's independent development plans. In the field of education, we also know that Blockchain also has a function to avoid the circulation of fake diplomas. One of the Media Lab Learning Initiatives, the Massachusetts Institute of Technology, has built a project that has an agenda to analyze the digitization of academic certificates circulated by authorized institutions so that they can determine the authenticity of data and facts. Many campuses around the world have decided to start implementing this technology for various facilities within their organizations, such as digital signatures and so on, to print diplomas for students who will graduate.

The use of Blockchain technology is very beneficial for students and also companies, the advantage that a student gets is that he can publish his diploma into the Blockchain after graduating from the University, then he can be glimpsed by several companies in a wide scope who are interested in needing his services, for perceived benefits. companies that can see and prove the authenticity of the student's diploma without taking a long time. Various related agencies to the government can also feel the same thing, namely being able to see the original evidence or not of the published diploma. So, this technology is indeed transparent and very safe and has also been trusted by many parties

Advances in Blockchain technology have supported many universities in providing data that is open to the public and has been validated in every registration activity carried out and witnessed directly by prospective students, and is equipped with a high level of security as well. With the presence of technology such as Blockchain, it is hoped that it can contribute to solving problems and also speeding up the document verification process, so it doesn't need to take a lot of time. Because the use of Blockchain technology can also narrow the space for despicable actions such as fraudulent fake diplomas.

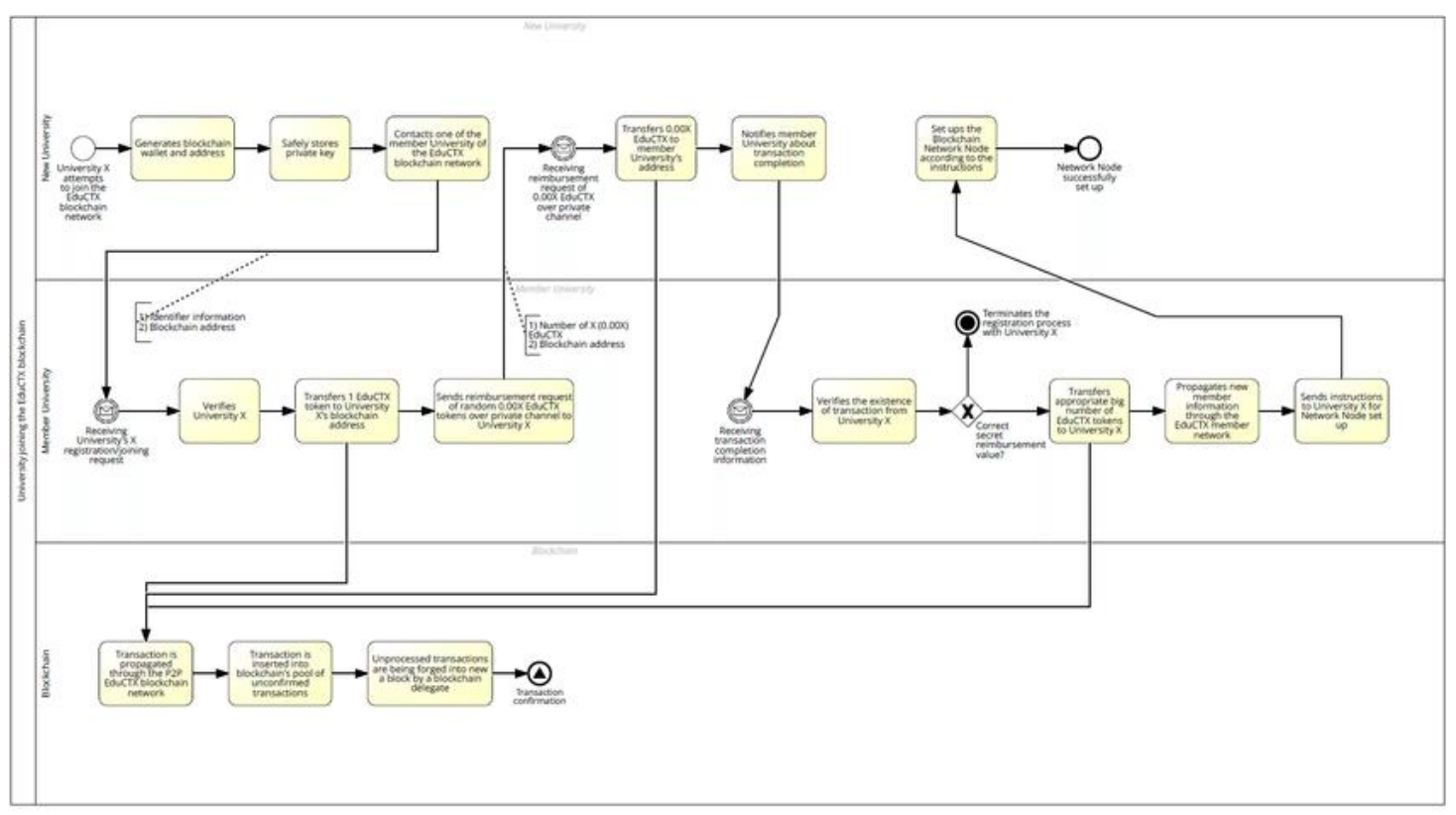

Figure 1. Flow of the New Student Registration Process in Higher Education using the Blockchain Network 
Several Stages in the Student registration process with Blockchain technology:

1. Prospective students who wish to register at their favorite universities can register online, students can visit the website or through the application and if they have filled in all their personal data correctly and completely through the online registration, then prospective students will get their registration number, candidate data The student will be automatically input into the Blockchain and this is the basis for online registration

2. Prospective students who have paid the registration fee will get a test card and can immediately take the test.

3. The test results will be checked by the admissions unit, meanwhile prospective students must wait for the test results to determine whether or not they are accepted at the University.

4. If you have received the test results and passed, then prospective students can reregister and make payments again and complete all files for registration.

5. Furthermore, the student admissions unit will check the documents and payments, if they are appropriate, it will create an ID for the student which will then be automatically recorded in the blockchain and can be used during lectures until graduation later.

6. Prospective students who have obtained an ID will receive a student card, as proof that the student in question is a student at the university.

7. The registration and scheduling unit will provide an orientation schedule as well as a first semester class schedule for students.

8. If you have gone through all the registration processes, the prospective student is officially accepted at the University of his choice.

\section{Implementation}

Today, many new technologies are emerging and being developed, one of which is Blockchain, which we are currently discussing. Blockchain is a technology like a ledger that also has a function for system distribution. In the medical world, Blockchain technology has also been introduced and has been widely used, ranging from electronic health registration, treatment, to assisting health management and much more, and can also make significant changes. One of the reasons for implementing Blockchain technology in the pharmaceutical industry is that it can provide certainty about the quality and quantity of drugs to be used. Not only that, this technology is also suitable to be combined with industrial or organizational applications, by bringing several advantages such as: transparency and authenticity of data, even Blockchain technology is reportedly being tested in the government sector.

Blockchain is a distributed system that is used to add and store data digitally. The first person to propose this technology was Satoshi Nakamoto in 2008, which is used to transact digitally, and what we know is cryptocurrency. Transactions that take place are peer-to-peer while validating transactions, where each block that is connected to each other will be marked with a timestamp and will not be editable, then will be distributed to the network. On Blockchain, only one part is verified according to the synchronization consensus, this process is open to the public and transparent.

Blockchain gave birth to the very first version, Blockchain 1.0, which has been used by Bitcoin which aims to solve problems in digital finance such as cryptocurrencies. The emergence of Bitcoin is indeed very amazing, thanks to Bitcoin, other digital currencies were also created such as Litecoin, Peercoin and so on, the digital currency is also similar to Bitcoin. At the beginning of 2013 there was a smart contract owned by Ethereum which could then provide the impetus for the creation of Blockchain version 2.0, this version carries the concept of crossmarket decentralization. 1 year ago, Blockchain version 3.0 was just created which has the function to help find solutions related to the use of non-financial industries, in every company system.

Thanks to the advantages possessed by Blockchain, there will be many fields that will benefit. As we know before, some of the advantages possessed by blockchains including can validate data, provide accurate information and cannot "randomize" data data that has been published and it has been proven that this technology can advance the business process, one 
example is There have been many educational institutions that apply them. In the world of education the registration process is the initial process lived by students,

As a requirement to enter the intended university, before starting learning activities, of course, after graduating from the acceptance selection, the students are officially accepted in the college and get ready for Following all learning activities, when they have graduated later, a student will receive a legal diploma because it has obeyed all the procedures from the beginning of registration until the last day he attended. At other universities have also activated Blockchain technology for recording all data.

The system at the time of registration will provide satisfactory services, such as: fast recording, good response, and fast transactions, in this case, prospective students will get a guarantee and also the authenticity of the diploma will be guaranteed when they graduate. When they are going through the study process, the various identities and activities they carry out during their studies will be automatically recorded, both from the first time they register, the first time they participate in learning activities until the last day of college. The student data in question includes: full name, student identification number, address, exam schedule, grades and much more.

The model on Blockchain technology that has been proposed as we discussed earlier is a business process agreement between one university and another. This model publishes information that is open to interested internal campus parties and also to students, the published data is managed in real time to keep it up-to-date and also a good verification process. Thus, various activity processes that occur in educational institutions, corporate agencies and in other sectors can implement the concept of Blockchain

\section{Conclusion}

The model on Blockchain technology that has been proposed as we discussed earlier is a business process agreement between one university and another. This model publishes information that is open to interested internal campus parties and also to students, the published data is managed in real time so that it is always up-to-date and also has a good verification process. Blockchain implementation in the prospective student registration system will be able to find solutions to overcome problems such as loss of data for prospective students who are undergoing the registration process to problems such as the circulation of fake diplomas. The emergence of this problem is due to invalid data, so it can create space for irresponsible people to misuse it. not only illegal institutions that can do that, but legal institutions can also follow in his footsteps.

Such are the various activities carried out by many institutions that apply Blockchain technology. This study aims to examine an activity such as registration of prospective students, learning activities to preparation for graduation, where these activities have been recorded by the Blockchain. Advances in Blockchain technology have supported many universities in providing data that is open to the public and has been validated in every registration activity carried out and witnessed directly by prospective students, and is equipped with a high level of security as well. The government can also play a role in controlling various activities in educational institutions. in the next opportunity, the researcher who will continue research on Blockchain technology which is being developed has plans to select data integration for universities. This journal is a form of initial step to go further and for future research we hope that Blockchain technology can already be used for learning transactions, financial transactions and so on.

\section{References}

[1] S. Ahmed and N. Ten Broek, "Blockchain could boost food security," Nature, vol. 550, no. 7674 , p. 43, 2017.

[2] T. Ahram, A. Sargolzaei, S. Sargolzaei, J. Daniels, and B. Amaba, "Blockchain technology innovations," in 2017 IEEE technology \& engineering management conference (TEMSCON), 2017, pp. 137-141

[3] K. Al Harthy, F. Al Shuhaimi, and K. K. J. Al Ismaily, "The upcoming Blockchain adoption 
in Higher-education: requirements and process," in 2019 4th MEC international conference on big data and smart city (ICBDSC), 2019, pp. 1-5.

[4] W. Al-Saqaf and N. Seidler, "Blockchain technology for social impact: opportunities and challenges ahead," J. Cyber Policy, vol. 2, no. 3, pp. 338-354, 2017.

[5] A. Azaria, A. Ekblaw, T. Vieira, and A. Lippman, "Medrec: Using blockchain for medical data access and permission management," in 2016 2nd international conference on open and big data (OBD), 2016, pp. 25-30.

[6] R. Bdiwi, C. De Runz, S. Faiz, and A. A. Cherif, "Towards a new ubiquitous learning environment based on blockchain technology," in 2017 IEEE 17th International Conference on Advanced Learning Technologies (ICALT), 2017, pp. 101-102.

[7] K. A. Clauson, E. A. Breeden, C. Davidson, and T. K. Mackey, "Leveraging Blockchain Technology to Enhance Supply Chain Management in Healthcare:: An exploration of challenges and opportunities in the health supply chain," Blockchain Healthc. today, 2018.

[8] R. Y. Garankina, E. R. Zakharochkina, I. F. Samoshchenkova, N. Y. Lebedeva, and A. $\mathrm{V}$ Lebedev, "Blockchain Technology and its Use in the Area of Circulation of Pharmaceuticals," J. Pharm. Sci. Res., vol. 10, no. 11, pp. 2715-2717, 2018.

[9] X. Gong, X. Liu, S. Jing, G. Xiong, and J. Zhou, "Parallel-education-blockchain driven smart education: Challenges and issues," in 2018 Chinese Automation Congress (CAC), 2019, pp. 2390-2395.

[10] A. Grech and A. F. Camilleri, Blockchain in education. Luxembourg: Publications Office of the European Union, 2017.

[11] I. Haq and O. M. Esuka, "Blockchain technology in pharmaceutical industry to prevent counterfeit drugs," Int. J. Comput. Appl., vol. 180, no. 25, pp. 8-12, 2018.

[12] M. B. Hoy, "An introduction to the blockchain and its implications for libraries and medicine," Med. Ref. Serv. Q., vol. 36, no. 3, pp. 273-279, 2017.

[13] S. Khezr, M. Moniruzzaman, A. Yassine, and R. Benlamri, "Blockchain technology in healthcare: A comprehensive review and directions for future research," Appl. Sci., vol. 9, no. 9, p. 1736, 2019.

[14] M. White, J. Killmeyer, and B. Chew, "Understanding basics of blockchain in government." 2017.

[15] M. Meyliana, C. Cassandra, H. A. E. Surjandy, E. F. Widjaja, H. Prabowo, and C. Joseph, "DEFYING THE CERTIFICATION DIPLOMA FORGERY WITH BLOCKCHAIN PLATFORM: A PROPOSED MODEL," in Proceedings of the International Conferences ICT, Society, and Human Beings 2019; Connected Smart Cities 2019; and Web Based Communities and Social Media 2019, 2019, pp. 63-71.

[16] A. Mikroyannidis, J. Domingue, M. Bachler, and K. Quick, "Smart blockchain badges for data science education," in 2018 IEEE Frontiers in Education Conference (FIE), 2018, pp. 1-5.

[17] V. Morabito, "Business innovation through blockchain," Cham Springer Int. Publ., 2017.

[18] S. Nakamoto, "Bitcoin: A peer-to-peer electronic cash system Bitcoin: A Peer-to-Peer Electronic Cash System," Bitcoin. org. Dispon. en https//bitcoin. org/en/bitcoin-paper, 2009.

[19] Q. K. Nguyen and Q. V. Dang, "Blockchain Technology for the Advancement of the Future," in 2018 4th international conference on green technology and sustainable development (GTSD), 2018, pp. 483-486. 